Published in final edited form as:

Am J Physiol Regul Integr Comp Physiol. 2006 August ; 291(2): R419-R428. doi:10.1152/ajpregu.

00864.2005.

\title{
Identification of neural circuits involved in female genital responses in the rat: A dual virus and anterograde tracing study
}

\author{
L. Marson ${ }^{1}$ and A Z Murphy 2,3 \\ ${ }^{1}$ Dept. of Surgery, Div. of Urology School of Medicine, Univ. North Carolina, Chapel Hill, NC \\ ${ }^{2}$ Dept. of Anatomy University of Maryland School of Medicine, Baltimore, MD \\ ${ }^{3}$ Dept. of Biology, Center for Behavioral Neuroscience, Georgia State University, Atlanta, GA
}

\section{Abstract}

The spinal and peripheral innervation of the clitoris and vagina are fairly well understood. However, little is known regarding supraspinal control of these pelvic structures. The multisynaptic tracer pseudorabies virus (PRV) was used to map the brain neurons that innervate the clitoris and vagina. In order to delineate forebrain input onto PRV labeled cells, the anterograde tracer biotinylated dextran amine (BDA) was injected into the medial preoptic nucleus (MPO), ventromedial nucleus of the hypothalamus (VMN) or the midbrain periaqueductal gray (PAG) 10 days prior to viral injections. These brain regions have been intimately linked to various aspects of female reproductive behavior. Four days after viral injections, into the vagina and clitoris PRV labeled cells were observed in the paraventricular nucleus, Barrington's nucleus, the A5 region, and the nucleus paragigantocellularis. At 5 days post-viral administration, additional PRV labeled cells were observed within the preoptic region, VMN, PAG and lateral hypothalamus. Anterograde labeling from the MPO terminated among PRV positive cells primarily within the dorsal paraventricular nucleus of the hypothalamus (PVN), ventrolateral VMN (VMNvl), caudal PAG and nucleus paragigantocellularis (nPGi). Anterograde labeling from the VMN terminated among PRV positive cells in the MPO and lateral/ventrolateral PAG. Anterograde labeling from the PAG terminated among PRV positive cells in the PVN, ventral hypothalamus and nPGi. Transynaptically labeled cells in the lateral hypothalamus, Barrington's nucleus and ventromedial medulla received innervation from all three sources. These studies, together, identify several CNS sites participating in the neural control of female sexual responses. They also provide the first data demonstrating a link between the MPO, VMNvl and PAG and CNS regions innervating the clitoris and vagina, providing support that these areas play a major role in female genital responses.

\section{Indexing Terms}

medial preoptic area; ventromedial hypothalamus; PAG; clitoris vagina; PRV

\begin{abstract}
Numerous anatomical, physiological and behavioral studies have been conducted to delineate the essential neural substrates that mediate female reproductive behavior $\left[13,15,56,58,{ }^{60},{ }^{70}\right.$, $71,72,83,84]$. These studies, conducted primarily in rodents, have identified several CNS regions involved in the sensory, autonomic and/or motor aspects of the lordosis reflex, a receptive behavior essential for vaginal penetration and pregnancy (e.g. 70]. More recent studies examining proceptive or solicitation behavior are being utilized to identify neural
\end{abstract}

\footnotetext{
Copyright $\odot 2006$ by the American Physiological Society.

Correspondence to: L Marson.
} 
circuits involved in pacing behavior $[21,25]$. Together, these studies have identified at least three supraspinal regions essential to various aspects of female reproductive behavior, including the ventromedial nucleus of the hypothalamus (VMN), the medial preoptic area (MPO), and the midbrain periaqueductal gray (PAG). The VMN is considered an integral component of the lordosis reflex; stimulation of the VMN in estrogen-primed animals facilitates the display of the lordosis reflex and lesions of this region significantly disrupt it $[56,68,69,70]$. In contrast to the VMN, bilateral lesions of MPO increase the occurrence of lordosis [e.g. 31,64,79] while stimulation of the MPO attenuates the display of the posture $[57,70]$. The MPO is also identified as a crucial area for the mediation of female pacing behavior $[25,102]$, and activation of the MPO results in increased blood flow to the vagina and increases vaginal wall tension [24]. Both the VMN and MPO send descending projections to the PAG $[26,41,52,63,69]$, and the PAG itself has been shown to play a facilitatory role in female reproductive behavior $[13,19,46,58,84,85,89]$. The PAG sends dense projections to the nucleus paragigantocellularis (nPGi), which subsequently projects to motoneurons in the thoracolumbar spinal region, that innervate the axial musculature as well as to lumbosacral neurons that innervate the pelvic organs $[17,18,27,29,51,61]$. The PAG also receives direct inputs from the lumbosacral spinal cord $[34,37,38,62,95]$, and may function to integrate ascending and descending information from multiple brain regions related to sexual behavior.

While the MPO, VMN and PAG have been implicated in some aspects of female sexual behavior, the role of these regions in regulating genital arousal and sexual climactic-like responses are unknown. Vaginal vasocongestion, muscle contractions and clitoral engorgement occur during genital arousal and sexual climax [5,24,35,43]. However, the CNS pathways that mediate these responses remain unknown. The MPO, VMN and PAG do not project directly to spinal regions that innervate spinal motor and preganglionic neurons involved in sexual responses. Therefore, modulation of genital responses by these regions must involve a multisynaptic pathway that relays in the brain. To delineate the anatomical pathways linking regions implicated in female sexual function (MPO, VMN and PAG) with the descending circuits that innervate the vagina and clitoris, the transneuronal tracer pseudorabies virus (PRV) was injected into the vagina and clitoris in combination with injections of the anterograde tracer biotin dextran amine into the MPO, VMN or PAG. The results of these studies identified several supraspinal-spinal circuits that may provide coordinated sensory, autonomic and hormonal modulation over female sexual responses.

\section{METHODS AND MATERIALS}

\section{Viral and Anterograde Tracer Injections}

All methods were performed in strict compliance with the Institutional Animal Care and Use Committee at University of Maryland, Baltimore. Female Sprague Dawley rats (Zivic Miller, $250-350 \mathrm{~g}$ ) were deeply anesthetized with chloral hydrate ( $4 \% \mathrm{w} / \mathrm{v}$; i.p.) and placed in a stereotaxic apparatus. The skull was adjusted so that bregma and lambda were on a horizontal plane. A small craniotomy was made and a glass micropipette $(25-50 \mu \mathrm{m})$ filled with biotinylated dextran amine (BDA; 10\% solution, 10,000 molecular weight, Sigma Chemicals) was lowered into one of the following regions: MPO (Bregma $-0.15 \mathrm{~mm}, 0.1 \mathrm{~mm}$ lateral and $7.1 \mathrm{~mm}$ ventral; $\mathrm{n}=8$ ), VMN (Bregma $3.5 \mathrm{~mm}, 0.75 \mathrm{~mm}$ lateral and $9 \mathrm{~mm}$ ventral; $\mathrm{n}=5$ ) or PAG (Lambda $+1.20,1.20$ lateral, $-3.5 \mathrm{~mm}$ ventral; $\mathrm{n}=8$ ). For the PAG injections, the manipulator was placed at a $7.5^{\circ}$ angle to avoid the sagittal sinus. Following BDA injection $(100 \mathrm{nl})$, the glass pipette remained in place for $10 \mathrm{~min}$ prior to removal to prevent backflow up the injection tract.

Ten days later, animals were reanesthetized with chloral hydrate and pseudorabies virus (PRV, $2-3 \times 10^{7}$ plaque forming units/ml [74], a gift from Dr. L. Enquist) was injected into the clitoris and vagina using a 25 gauge Hamilton syringe. Each female received a single injection into 
the clitoris $(0.5-1 \mu \mathrm{l})$ and two injections into the ventral region of the vagina $(\sim 1 \mathrm{~cm}$ from the vaginal orifice, $1 \mu \mathrm{l}$ each). The needle remained in place for $1 \mathrm{~min}$ post-injection. After withdrawal of the needle, pressure was applied to the injection site using a cotton tip applicator to prevent leakage of the virus to the surrounding muscle. Both organs were injected in order to label the majority of CNS neurons that are engaged during genital arousal and climacticlike responses $[5,26,37,45]$.

\section{Immunocytochemistry}

At the end of the survival period, animals were given an overdose of sodium pentobarbital and perfused transcardially (descending aorta clamped) with $250 \mathrm{ml}$ of $0.9 \%$ sodium chloride containing $2 \%$ sodium nitrite solution followed by $300 \mathrm{ml}$ of $4 \%$ paraformaldehyde in $0.1 \mathrm{M}$ phosphate buffer containing 2\% acrolein (Polyscience). A final rinse with the sodium chloride/ sodium nitrite solution was used to remove any residual acrolein from the animal. Brains were removed and placed in $30 \%$ sucrose solution until sectioned. Sections were cut using a freezing microtome at $25 \mu \mathrm{m}$, collected in cryoprotectant-antifreeze solution and stored at $-20^{\circ} \mathrm{C}$ until immunocytochemical processing.

A 1:6 series through the rostrocaudal axis of the brain was processed for BDA and PRV immunoreactivity. BDA was always visualized first as a black reaction product using nickelenhanced diaminobenzadine (Ni-DAB); PRV was always visualized second as a brown reaction product using non-enhanced DAB (see below). Spinal cord sections (1:4 series) through the L6/S1 level were processed for PRV immunoreactivity.

Sections were removed from the cryoprotectant-antifreeze solution, rinsed extensively in potassium phosphate-buffered saline (0.1M KPBS, $\mathrm{pH} 7.4$ ) and then reacted for $15 \mathrm{~min}$ in $1 \%$ sodium borohydride to remove excess aldehydes. Sections were incubated in goat anti-biotin antibody (1:60,000 dilution, Vector Labs, Burlington, CA) in KPBS containing $0.4 \%$ triton $\times$ for $1 \mathrm{hr}$ at room temperature followed by $48 \mathrm{hr}$ at $4^{\circ} \mathrm{C}$. After rinsing, the tissue was incubated for $1 \mathrm{hr}$ in rabbit anti-goat (1:600 dilution, Vector Labs,), followed by a $1 \mathrm{hr}$ incubation in avidin-biotin peroxidase complex (1:10; ABC Elite Kit, Vector Labs). After rinsing, BDA was visualized as a blue-black reaction product using a nickel-sulfate intensified 3,3'diaminobenzadine solution containing $0.08 \%$ hydrogen peroxide in $0.175 \mathrm{M}$ sodium acetate buffer. The reaction product was terminated after $7-25 \mathrm{~min}$ by rinsing in sodium acetate buffer.

Cells containing the pseudorabies virus were identified using a rabbit anti-PRV antibody (1:200,000 dilution, kindly donated by Dr. Lynn Enquist). Sections were rinsed several times in KPBS and then incubated for $1 \mathrm{hr}$ in primary antibody directed against PRV at room temperature followed by $48 \mathrm{hrs}$ at $4^{\circ} \mathrm{C}$. Secondary and $\mathrm{ABC}$ reactions were as stated above. PRV was visualized as a brown reaction product using a 3,3'-diaminobenzadine solution containing $0.08 \%$ hydrogen peroxide in tris buffer. Sections were mounted onto gelatin-subbed slides and coverslipped using DPX.

\section{Data Presentation}

The distribution of PRV neurons were plotted using a Nikon Drawing Tube attached to a Nikon Optiphot microscope. Plots were imported into the computer using the Waccom Drawing Tablet and Adobe Illustrator 10.0 software. Color photomicrographs were generated using a Synsys camera attached to a Nikon Eclipse E800 microscope. Images were captured using Adobe Photoshop 7.0. Alterations to images were strictly limited to enhancement of brightness/ contrast. 


\section{RESULTS}

\section{Distribution of PRV labeled neurons in the spinal cord}

Following a 4 day survival period spinal PRV labeling was confined to the region containing the sacral parasympathetic nucleus and dorsal gray commissure with an occasional PRV positive cell in the dorsal horn and intermediate gray (Figure 1, spinal cord, green dots). After 5 days survival PRV positive neurons were widely distributed in the spinal cord (Figure 1, spinal cord black dots). Regions containing PRV labeling included the superficial (laminae I and II), medial and lateral regions of the dorsal horn, lateral gray including the sacral parasympathetic nucleus, the dorsal gray commissure and intermediomedial nucleus, the intermediate gray (laminae V, VI and VII) and ventral horn.

\section{Distribution of PRV labeled neurons in the brain}

Injections of PRV into the clitoris and vagina resulted in viral positive cells in selective regions of the brain. Following a 4 day survival period, PRV containing cells (Figure 1, green dots) were primarily observed in the dorsolateral region of the paraventricular nucleus (PVN) (Figure 2A), Barrington's nucleus, A5 (Figure 2B), rostral ventromedial medulla (RVM) including the raphe magnus and the ventral gigantocellular reticular formation, and the ventral lateral medulla primarily in the nucleus paragigantocellularis (nPGi) (Figure 2C). In addition, PRV positive cells were occasionally localized in the lateral hypothalamus (dorsal and lateral to the fornix), caudal ventrolateral PAG, raphe pallidus and raphe obscurus (Figure 1, green dots).

After 5 day survival, more PRV containing cells were observed in the areas described above as well as additional brain regions (Figure 1, black dots). In the forebrain numerous PRV positive cells were noted throughout the lateral hypothalamus including PRV cells that were clustered around the fornix and in the parvocellular PVN. In addition, PRV positive cells were present in the MPO including the medial preoptic nucleus (MPN), retrochiasmatic area and ventrolateral VMN (VMNvl). Fewer PRV cells were observed scattered in the ventral portion of the bed nucleus of the stria terminalis, zona inercta, caudal medial amygdala and dorsal and ventral hypothalamic area. In the midbrain and pons, numerous PRV positive cells were found in the dorsal, lateral and ventrolateral PAG, Barrington's nucleus, A7 / Kolliker- Fuse region, lateral lemniscus and the pontine reticular formation including the area containing the subcoeruleus. In the medulla, PRV containing neurons were located in A5, RVM, nPGi and nucleus tractus solitarii (NTS). PRV labeling in the locus coeruleus (LC) was always inconsistent.

\section{MPO output onto PRV labeled cells}

MPO projections-MPO injection sites spread from $0.3 \mathrm{~mm}$ to $1.4 \mathrm{~mm}$ caudal to bregma and did not spread into the lateral preoptic area. The data are described from analysis of 3 cases that had overlapping injection sites that were centered $0.8 \mathrm{~mm}$ caudal to bregma (Figure $4 \mathrm{~A}$ ). BDA injections resulted in dense anterograde fiber labeling similar to that previously described $[52,63,77,78,90,91]$. Briefly, ascending BDA fibers ran dorsal to the MPO and innervated the bed nucleus of the stria terminalis. BDA fibers in the ventral hypothalamus coursed dorsal to the optic tract and innervated the caudal medial amygdala. A few BDA fibers and varicosities were found in the dorsal and medial PVN. A dense projection of BDA fibers was observed in the VMNvl. Descending fibers coursed through the posterior hypothalamus and periventricular fiber system. In the brainstem, BDA fibers were localized in the ventral tegmental region and dorsal to the substantia nigra. Numerous fibers were found running vertically through the medial and central PAG, and BDA fibers and terminals innervated the caudal dorsal, lateral and ventrolateral PAG. A dense projection from the MPO was observed in Barrington's nucleus. A moderate projection from the MPO was noted in the dorsal raphe and RVM. A few 
scattered fibers were always present in the ventral part of the LC, subcoeruleus, A5, nPGi and NTS.

MPO output onto PRV labeled cells-In the hypothalamus numerous BDA fibers were intermingled with PRV positive cells in the dorsal, lateral and posterior hypothalamic areas. A close association between BDA fibers and varicosities and PRV labeled neurons was noted in the perifornical region of the lateral hypothalamus, dorsal PVN and VMNvl (Figure 4B). In the rostral PAG, BDA fibers were located primarily medial to the PRV labeled cells. More caudally in the PAG, MPO projections preferentially terminated among PRV labeled cells in the lateral and ventrolateral PAG, in Barrington's nucleus and the subcoeruleus region. While fewer BDA fibers projected to the A5, nPGi (Figure 4C) and rostral ventromedial medulla (Figure 4D), BDA fibers were consistently found in close apposition to PRV cells in these regions. No association of BDA fibers and PRV labeled cells was noted in the locus coeruleus, raphe obscurus or raphe pallidus.

\section{VMNvl output onto PRV labeled cells}

VMNvl output-Projections from the VMN were mapped in two animals that had similar injections sites in the ventral part of the VMN $(\sim 2.4-3.8 \mathrm{~mm}$ caudal to bregma) that did not diffuse into the more dorsal VMN (Figure 5A). BDA labeled ascending fibers terminated primarily in the BNST, MPO, including the MPN and the ventral preoptic area. BDA fibers were also found in the medial amygdala, lateral hypothalamus, retrochiasmatic area and paraventricular thalamic nuclei. Only a few BDA fibers were found in the ventral PVN near the $3^{\text {rd }}$ ventricle. These studies confirm previous mapping of VMN outputs $[45,87]$. The descending fiber system was not as pronounced as the ascending fiber system. Fibers traveled close to the $3^{\text {rd }}$ ventricle in the periventricular fiber system. A few fibers were also noted in the ventral/posterior hypothalamus. In the midbrain, BDA labeled fibers terminated densely in the dorsal, lateral and ventrolateral PAG. More caudally, BDA labeling was found in the lateral dorsal tegmental region and as well as the ventral tegmental area. Occasional BDA fibers were found in Barrington's nucleus, RVM and nPGi.

VMNvl output onto PRV labeled cells-BDA fibers and PRV positive cells consistently overlapped in the MPO (Figure 5C), including the MPN, and the lateral hypothalamus. A moderate overlap was observed in the ventral preoptic area. In the midbrain, VMNvl fibers terminated heavily among PRV positive cells in the lateral and ventrolateral PAG and Barrington's nucleus (Figure 5B). A minor overlap was also present in the retrochiasmatic area and RVM including the raphe magnus and parapyramidal region of the medulla. No overlap of BDA fibers and PRV labeled cells was found in other brain regions including the PVN, arcuate nucleus, amygdala, A5 and nPGi.

\section{PAG output onto PRV cells}

PAG output-In 3 animals the BDA spread through the dorsal, lateral and ventral PAG but was confined to one side; in 2 animals the BDA injection site was more localized to the dorsal and dorso-lateral PAG and did not spread to the ventrolateral and lateral portions of the PAG. All injection sites mapped were centered $\sim 6.0-7.6 \mathrm{~mm}$ caudal to bregma (Figure 6A) and resulted in anterograde labeling within the lateral preoptic area, ventral hypothalamic area, lateral hypothalamus and zona incerta. Fibers were also noted in the anterior and dorsal hypothalamus and many BDA fibers ran dorsal to the optic tract coursing towards the amygdala. A small innervation of BDA fibers was present in the MPO including the MPN and the dorsal PVN. In the brainstem, heavy anterograde labeling was observed in Barrington's nucleus, subcoeruleus, A5, ventrolateral medulla including the nPGi and RVM. A small projection to locus coeruleus and NTS was also observed. 
Injections that were confined to the caudal dorsal/dorsolateral PAG (Figure 6A) produced a similar labeling pattern to that described above, however there were some differences. BDA fibers were primarily localized in the lateral preoptic area, lateral hypothalamus, dorsal hypothalamus, zona incerta, dorsal to the optic tract, and anterior hypothalamic area. Very few fibers were present in the MPO and PVN. BDA fibers were also observed in the ventral tegmental area and dorsal to the substantia nigra and geniculate nucleus. Similar to that noted above, descending BDA fibers were present primarily in the A5, RVM and nPGi. Projections from the dorsal/dorsolateral PAG did not result in a large innervation of the sexual dimorphic MPO, subcoeruleus region or Barrington's nucleus suggesting that these areas receive input primarily from the ventrolateral PAG. These studies confirm previous neuroanatomical studies reporting specific topographically defined PAG inputs and outputs $[1,2,3,6]$.

PAG output onto PRV cells-Anterograde labeling from the PAG terminated among PRV labeled cells in the lateral and ventral hypothalamic area. While few PRV cells were found in the lateral preoptic area, they were always closely apposed to BDA fibers (Figure $6 \mathrm{~B}$ and C). A minor overlap of BDA fibers and PRV positive cells was observed in the caudal PVN. The major overlap in the brainstem was found in Barrington's nucleus, subcoeruleus, A5, RVM (Figure 6D) and nPGi (Figure 6D). In some animals a few PRV labeled cells and BDA fibers were observed in the locus coeruleus.

Injections into the caudal dorsal/dorsolateral PAG resulted in a large overlap of BDA fibers and PRV positive cells in the lateral hypothalamus and the dorsal and posterior hypothalamus. A consistent overlap was also found within the lateral preoptic area with a smaller overlap in the caudal PVN. In the brainstem, a large population of PAG output fibers terminated heavily among PRV neurons in the RVM, nPGi, and A5. However, anterogradely labeled PAG fibers primarily ran medial to PRV positive cells in Barrington's nucleus.

\section{DISCUSSION}

Transneuronal tracing with PRV was used to identify supraspinal regions involved in the central regulation of the clitoris and vagina that may be associated with sexual responses. Anterograde tracing from the MPO, VMNvl and PAG, in combination with PRV, was used to determine if neurons transynaptically labeled from the sexual organs receive preferential inputs from brain regions previously shown to mediate various aspects of female reproductive behavior. The present studies provide the first data demonstrating a direct link between the MPO, VMNvl and PAG with CNS regions innervating the clitoris and/or vagina, providing support that these areas play a major role in female genital responses. The present results also demonstrate that several brain sites, including the lateral hypothalamus, PVN, Barrington's nucleus, A5, RVM and nPGi, provide input to the clitoris and/or vagina, and receive input from more than one brain site involved in sexual behavior. These brain regions may participate in the integration of hormonal and sensory signals related to female arousal and muscle responses that accompany sexual climactic-like reflexes.

\section{PRV labeling in the brain}

The retrograde transynaptic tracer (PRV) was used to identify CNS regions that innervate the clitoris and/or vagina $[7,8,9,74,79]$. These data confirm and extend previous studies describing CNS pathways that innervate female pelvic organs. Brain areas labeled with PRV following a 4 day survival time included the dorsolateral PVN, Barrington's nucleus, A5, raphe magnus and ventrolateral medulla suggesting that these regions make direct contacts with spinal efferent pathways mediating genital organ function. These results confirm anatomical tracing studies using conventional tracers showing that these regions provide direct input to parasympathetic and sympathetic preganglionic regions, motoneurons and/or interneurons in 
the lumbosacral spinal cord that are part of the circuit regulating sexual reflexes $[12,18,27$, $\left.28,{ }^{44}, 45,51,52,59,100\right]$. Brain regions which were only labeled following a 5 day survival included the bed nucleus of the stria terminalis, MPO, medial amygdala, retrochiasmatic area, VMNvl, dorsal and lateral PAG, and A7, and most likely represent sites projecting to the brain regions that innervate spinal circuits that regulate the clitoris and/or vagina.

The majority of transynaptically labeled neurons were found in brain regions previously shown to be involved in the descending innervation of the back muscles, uterus, clitoris and cervix $[17,42,51,67]$. However, some differences were found in the present study compared to previous viral tracing studies of the reproductive organs. Transynaptically labeled neurons were not observed in the VMNvl after PRV injections into the clitoris [50], suggesting that the PRV positive neurons in the VMNvl in the present study may have been labeled from the vagina, although further studies examining vaginal projections are required to confirm this hypothesis. Injections of PRV into the corpus cavernosum, prostate or perineal muscles in the male rat did not result in PRV labeled neurons in the VMNvl even when many forebrain structures were labeled $[54,55,65]$. Therefore, PRV labeling of the VMNvl appears to be specific to females. The dorsal motor nucleus of the vagus was labeled after injections of PRV into uterine cervix but not labeled in the present study [42,66,67], labeling of this structure following uterine, but not clitoral and/or vaginal injections, supports the anatomical and physiological studies demonstrating vagal input to the uterus $[32,66]$.

Several brain regions labeled with PRV in the present study have been shown previously to be activated during female sexual behavior. Vaginocervical stimulation, induced by artificial mechanical stimuli or during mating, resulted in c-fos expression in the bed nucleus of the stria terminalis, medial amygdala, MPO, PVN, lateral hypothalamus, PAG, and nPGi [21,72,73, $75,83,94,97]$. Further studies examining the specific role of each of the brain sites are required to understand their contribution to specific aspects of sexual function.

Brain areas containing PRV neurons that receive multiple inputs-In the forebrain, PRV neurons were consistently found in the lateral hypothalamus in close association with outputs from the MPO, VMNvl and the PAG. The densest overlap between anterograde labeling and PRV+ cells was within the caudal lateral hypothalamus, surrounding the fornix. The lateral hypothalamus is involved in visceral sensory information, somatomotor control, feeding behavior and wakefulness $[11,22,36,76]$. The LH may also be important for some aspects of male sexual behavior. For example, serotonin released into the LH during ejaculation appears to regulate the post ejaculatory refractory period and injection of selective serotonin reuptake inhibitors into the LH delays copulation and ejaculation $[33,47,48]$. In both males and females, neurons in the LH are activated with sexual behavior [21,72,73,75,83,94]. No direct evidence for a role of the lateral hypothalamus in female sexual behavior has been documented to date. However, we propose that the LH may integrate hormonal, sensory and autonomic inputs in order to modulate the arousal level of the animal during reproductive behavior. This hypothesis is based on several factors (1) the dense PRV labeling in the LH from the clitoris and/or vagina, (2) inputs from the MPO, VMNvl and PAG that terminated in close apposition to the PRV labeled cells in the LH and (3) the role of the LH in sleep/wakefulness.

Transynaptically labeled PRV neurons that received inputs from both the MPO and the VMNvl were primarily localized to the lateral and ventrolateral PAG, confirming previous reports that the MPO and the VMNvl project to specific regions of the PAG $[41,53,63,77,87]$. The lateral and ventrolateral PAG have long been implicated in lordosis [14,59,84,85], and previous studies using PRV injected into the clitoris, uterus or back muscles reported similar labeling of ventrolateral PAG neurons at early survival times [17,51,67]. Very few neurons in the lateral PAG project directly to the spinal cord [52,61], therefore the majority of PRV labeled neurons in the PAG were most likely transynaptically labeled from the ventral medulla, including the 
nPGi and raphe magnus, regions that show a dense direct spinal projection using conventional anatomical tracing techniques $[27,28,44,45,49,52,63,96]$. Interestingly, anterograde labeling from the MPO and VMNvl was localized predominantly in PAG regions containing PRV positive cells, suggesting a direct MPO/VMN - PAG - nPGi- spinal cord circuit that modulates female sexual responses. Some PAG areas containing PRV positive cells also receive direct inputs from the lumbosacral spinal cord [34,62,95], suggesting a direct feedback circuit for the coordination of somatosensory input with descending modulatory input from the forebrain.

Pseudorabies virus positive cells in the PVN, particularly the parvocellular region, received moderate inputs from the MPO and the PAG. PVN neurons are consistently labeled after injections of PRV into the reproductive organs $[42,50,55,67]$ and are also labeled after injection of PRV into the heart and kidney etc. [e.g. 88,92]. The parvocellular neurons have long been linked to cardiovascular regulation, and these neurons have also been shown to regulate other autonomic functions. PVN neurons are activated during sex [e.g. 21,72,73,75] and may be involved in the increased circulating levels of oxytocin reported during sexual behavior [10, 22]. The PVN is also reportedly activated with orgasm in women with spinal cord injury [38]. The firing rate of PVN neurons increases with uterine distension, which may account for the release of circulating hormones associated with pregnancy and parturition. Oxytocin PVN neurons project directly to the lumbosacral spinal cord $[86,98,99,100]$, and are transneuronally labeled after injections of PRV into the vagina, further suggesting the PVN may be directly involved in the regulation of genital organ function.

Barrington's nucleus also received innervation from all three sources. The primary role of Barrington's nucleus is to regulate continence and voiding [4,93]. Since this basic function would interfere with the process of sexual behavior, it is likely that overlapping pathways function to coordinate micturition and sexual behavior. Further studies are required to confirm this observation and to address the role of Barrington's nucleus in female sexual responses. Other areas that project to the clitoris/vagina and receive inputs from the MPO, VMNvl and PAG include the ventromedial and ventrolateral medulla. Neurons in the ventrolateral medulla, including the nPGi, mediate contractions of the skeletal muscles of the back, respond to genital stimulation and regulate the descending inhibition of the urethrogenital reflex $[15,30,59,70$, $81,82,103]$. The raphe magnus, and its descending projections to the dorsal horn of the spinal cord, constitute the endogenous descending analgesia circuit; therefore, forebrain and PAG input to the raphe magnus may serve to increase somatosensory thresholds during reproductive behavior $[16,39,41,101]$.

\section{Summary}

Transneuronal tracing with PRV was used to identify brain regions involved in the regulation of clitoral and vaginal responses during sexual arousal and climactic-like responses. The results of these studies are the first to link input from the MPO, VMNvl and PAG with neurons transynaptically labeled from the clitoris and vaginal, and establish a potential circuit for the elaboration of female sexual responses. Input from the MPO, VMN and PAG may also allow for the coordination of hormonal input with sensory, autonomic and motor output. Further studies examining the specific contribution of these brain circuits and their neurotransmitters in regulating female sexual responses is required.

\section{Acknowledgments}

Grant Support: NIH grants NS39166 to LM and MH59197 and DA16272 to AZM. 


\section{Literature cited}

1. Akaishi T, Jiang ZY, Sakuma Y. Ascending fiber projections from the midbrain central gray to the ventromedial hypothalamus in the rat. Exp Neurol 1988;99(2):247-258. [PubMed: 3338520]

2. Bandler R, McCulloch T. Afferents to a midbrain periaqueductal grey region involved in the 'defense reaction' in the cat as revealed by horseradish peroxidase. II. The diencephalon. Behav Brain Res 1984;13(3):279-285. [PubMed: 6542409]

3. Bandler R, McCulloch T, Dreher B. Afferents to a midbrain periaqueductal grey region involved in the 'defence reaction' in the cat as revealed by horseradish peroxidase. I. The telencephalon Brain Res 1985;330(1):109-119.

4. Barrington FF. The effects of lesions of the hind-and mid-brain on micturition in the cat. J Exp Physiol 1925;15:81-102.

5. Bohlen JG, Held JP, Sanderson MO, Ahlgren A. The female orgasm: pelvic floor contractions. Arch Sex Behav 1982;11:376-386.

6. Cameron AA, Khan IA, Westlund KN, Willis WD. The efferent projections of the periaqueductal gray in the rat: a Phaseolus vulgaris-leucoagglutinin study. II. Descending projections. J Comp Neurol 1995;351(4):585-601. [PubMed: 7721985]

7. Card JP. Practical considerations for the use of pseudorabies virus in transneuronal studies of neural circuitry. Neurosci Biobehav Rev 1998;22:685-694. [PubMed: 9809304]

8. Card JP, Rinaman L, Lynn RB, Lee BH, Meade RP, Miselis RR, Enquist LW. Pseudorabies virus infection of the rat central nervous system: ultrastructural characterization of viral replication, transport, and pathogenesis. J Neurosci 1993;13(6):2515-2539. [PubMed: 8388923]

9. Card JP, Rinaman L, Schwaber JS, Miselis RR, Whealy ME, Robbins AK, Enquist LW. Neurotropic properties of pseudorabies virus: uptake and transneuronal passage in the rat central nervous system. J Neurosci 1990;10(6):1974-1994. [PubMed: 2162388]

10. Carmichael MS, Humbert R, Dixen J, Palmisano G, Greenleaf W, Davidson JM. Plasma oxytocin increases in the human sexual response. J Clin Endocrinol Metab 1987;64(1):27-31. [PubMed: 3782434]

11. Chemelli RM, Willie JT, Sinton CM, Elmquist JK, Scammell T, Lee C, Richardson JA, Williams SC, Xiong Y, Kisanuki Y, Fitch TE, Nakazato M, Hammer RE, Saper CB, Yanagisawa M. Narcolepsy in orexin knockout mice: molecular genetics of sleep regulation. Cell 1999;98(4):437-451. [PubMed: 10481909]

12. Chinapen S, Swann JM, Steinman JL, Komisaruk BR. Expression of c-fos in lumbosacral spinal cord in response to vaginocervical stimulation in rats. Neurosci Lett 1992;145(1):93-96. [PubMed: 1461575]

13. Coolen LM, Peters HJPW, Veening JG. Fos-immunoreactivity in the rat brains following consummatory elements of sexual behavior: A sex comparison. Brain Res 1996;738:67-82. [PubMed: 8949929]

14. Cottingham SL, Pfaff DW. Electrical stimulation of the midbrain central gray facilitates lateral vestibulospinal activation of back muscle EMG in the rat. Brain Res 1987;421(1-2):397-400. [PubMed: 3690283]

15. Cottingham SL, Femano PA, Pfaff DW. Electrical stimulation of the midbrain central gray facilitates reticulospinal activation of axial muscle EMG. Exp Neurol 1987;97(3):704-724. [PubMed: 3622719]

16. Crowley WR, Rodriguez-Sierra JF, Komisaruk BR. Analgesia induced by vaginal stimulation in rats is apparently independent of a morphine-sensitive process. Psychopharmacol (Berl) 1977;54(3):223225.

17. Daniels D, Miselis RR, Flanagan-Cato LM. Central neuronal circuit innervating the lordosisproducing muscles defined by transneuronal transport of pseudorabies virus. J Neurosci 1999;19(7): 2823-2833. [PubMed: 10087093]

18. Du HJ. Medullary neurons with projections to lamina $X$ of the rat as demonstrated by retrograde labeling after HRP microelectrophoresis. Brain Res 1989;505(1):135-140. [PubMed: 2611667]

19. Dudley CA, Moss RL. Effects of a behaviorally active LHRH fragment and septal area stimulation on the activity of mediobasal hypothalamic neurons. Synapse 1987;1(3):240-247. [PubMed: 3333200] 
20. Erskine MS. Solicitation behavior in the estrous female rat: a review. Horm Behav 1989;23:473-502. [PubMed: 2691387]

21. Flanagan-Cato LM, McEwen BS. Pattern of Fos and Jun expression in the female rat forebrain after sexual behavior. Brain Res 1995;673(1):53-60. [PubMed: 7757479]

22. Flanagan LM, Pfaus JG, Pfaff DW, McEwen BS. Induction of FOS immunoreactivity in oxytocin neurons after sexual activity in female rats. Neuroendocrinol 1993;58(3):352-358.

23. Gerashchenko D, Shiromani PJ. Different neuronal phenotypes in the lateral hypothalamus and their role in sleep and wakefulness. Mol Neurobiol 2004;29(1):41-59. [PubMed: 15034222]

24. Giuliano F, Allard J, Compagnie S, Alexandre L, Droupy S, Bernabe J. Vaginal physiological changes in a model of sexual arousal in anesthetized rats. Am J Physiol Regul Integr Comp Physiol 2001;281 (1):R140-R149. [PubMed: 11404287]

25. Guarraci FA, Megroz AB, Clark AS. Paced mating behavior in the female rat following lesions of three regions responsive to vaginocervical stimulation. Brain Res 2004;999:40-52. [PubMed: 14746920]

26. Hennessey AC, Camak L, Gordon F, Edwards DA. Connections between the pontine central gray and the ventromedial hypothalamus are essential for lordosis in female rats. Behav Neurosci 1990;104 (3):477-488. [PubMed: 2354041]

27. Holstege G. Some anatomical observations on the projections from the hypothalamus to brainstem and spinal cord: an HRP and autoradiographic tracing study in the cat. J Comp Neurol 1987;260(1): 98-126. [PubMed: 3496365]

28. Holstege G. Descending motor pathways and the spinal motor system: limbic and non-limbic components. Prog Brain Res 1991;87:307-421. [PubMed: 1678191]

29. Holstege G, Tan J. Supraspinal control of motoneurons innervating the striated muscles of the pelvic floor including urethral and anal sphincters in the cat. Brain 1987;110(5):1323-1344. [PubMed: 3676703]

30. Hornby JB, Rose JD. Responses of caudal brain stem neurons to vaginal and somatosensory stimulation in the rat and evidence of genital nociceptive interactions. Exp Neurol 1976;51:363-376. [PubMed: 1269566]

31. Hoshina Y, Takeo T, Nakano K, Sato T, Sakuma Y. Axon-sparing lesion of the preoptic area enhances receptivity and diminishes proceptivity among components of female rat sexual behavior. Behav Brain Res 1994;61(2):197-204. [PubMed: 8037867]

32. Hubscher $\mathrm{CH}$, Berkley KJ. Spinal and vagal influences on the responses of rat solitary nucleus neurons to stimulation of uterus, cervix and vagina. Brain Res 1995;702(1-2):251-254. [PubMed: 8846084]

33. Hull EM, Muschamp JW, Sato S. Dopamine and serotonin: influences on male sexual behavior. Physiol Behav 2004;83(2):291-307. [PubMed: 15488546]

34. Keay KA, Feil K, Gordon BD, Herbert H, Bandler R. Spinal afferents to functionally distinct periaqueductal gray columns in the rat: an anterograde and retrograde tracing study. J Comp Neurol 1997;385(2):207-229. [PubMed: 9268124]

35. Kim SW, Jeong S-J, Munarriz R, Kim NN, Goldstein I, Traish AM. An in vivo rat model to investigate female vaginal arousal response. J Urol 2004;171:1357-1361. [PubMed: 14767348]

36. Kohler C, Swanson LW. Acetylcholinesterase-containing cells in the lateral hypothalamic area are immunoreactive for alpha-melanocyte stimulating hormone (alpha-MSH) and have cortical projections in the rat. Neurosci Lett 1984;49(1-2):39-43. [PubMed: 6493596]

37. Klop EM, Mouton LJ, Hulsebosch R, Boers J, Holstege G. In cat four times as many lamina I neurons project to the parabrachial nuclei and twice as many to the periaqueductal gray as to the thalamus. Neurosci 2005;134(1):189-197.

38. Klop EM, Mouton LJ, Kuipers R, Holstege G. Neurons in the lateral sacral cord of the cat project to periaqueductal grey, but not to thalamus. Eur J Neurosci 2005;21(8):2159-2166. [PubMed: 15869512]

39. Komisaruk BR, Whipple B. Vaginal stimulation-produced analgesia in rats and women. Ann N Y Acad Sci 1986;467:30-39. [PubMed: 3460470]

40. Komisaruk BR, Whipple B, Crawford A, Liu WC, Kalnin A, Mosier K. Brain activation during vaginocervical self-stimulation and orgasm in women with complete spinal cord injury: fMRI evidence of mediation by the vagus nerves. Brain Res 2004;1024(1-2):77-88. [PubMed: 15451368] 
41. Krieger MS, Conrad LC, Pfaff DW. An autoradiographic study of the efferent connections of the ventromedial nucleus of the hypothalamus. J Comp Neurol 1979;183(4):785-815. [PubMed: 762273]

42. Lee JW, Erskine MS. Pseudorabies virus tracing of neural pathways between the uterine cervix and CNS: effects of survival time, estrogen treatment, rhizotomy, and pelvic nerve transection. J Comp Neurol 2000;418(4):484-503. [PubMed: 10713575]

43. Levin RJ. The mechanisms of human female sexual arousal. ANN Rev Sex Res 1992;3:1.

44. Loewy AD. Descending pathways to the sympathetic preganglionic neurons. Prog Brain Res 1982;57:267-277. [PubMed: 6296919]

45. Loewy AD, Wallach JH, McKellar S. Efferent connections of the ventral medulla oblongata in the rat. Brain Res 1981;228(1):63-80. [PubMed: 7023615]

46. Lonstein JS, Stern JM. Site and behavioral specificity of periaqueductal gray lesions on postpartum sexual, maternal, and aggressive behaviors in rats. Brain Res 1998;804(1):21-35. [PubMed: 9729249]

47. Lorrain DS, Matuszewich L, Friedman RD, Hull EM. Extracellular serotonin in the lateral hypothalamic area is increased during the postejaculatory interval and impairs copulation in male rats. J Neurosci 1997;17(23):9361-9366. [PubMed: 9364081]

48. Lorrain DS, Riolo JV, Matuszewich L, Hull EM. Lateral hypothalamic serotonin inhibits nucleus accumbens dopamine: implications for sexual satiety. J Neurosci 1999;19(17):7648-7652. [PubMed: 10460270]

49. Loyd D, Murphy AZ. Sex differences in the anatomical and functional organization of the midbrain periaqueductal gray-rostral ventromedial medullary pathway: A potential circuit mediating the sexually dimorphic actions of morphine. J. Comp. Neurol. (submitted).

50. Marson L. Central nervous system neurons identified after injection of pseudorabies virus into the rat clitoris. Neurosci Lett 1995;190(1):41-44. [PubMed: 7624051]

51. Marson L, Cai R, Makhanova N. Identification of spinal neurons involved in the urethrogenital reflex in the female rat. J Comp Neurol 2003;462(4):355-370. [PubMed: 12811806]

52. Marson L, Foley KA. Identification of neural pathways involved in genital reflexes in the female: a combined anterograde and retrograde tracing study. Neurosci 2004;127(3):723-736.

53. Marson L, McKenna KE. A role for 5- hydroxytryptamine in descending inhibition of sexual reflexes. Exp Brain Res 1992;88:313-320. [PubMed: 1577105]

54. Marson L, McKenna KE. CNS cell groups involved in the control of the ischiocavernosus and bulbospongiosus muscles: A transneuronal tracing study using pseudorabies virus. J Comp Neurol 1996;374:161-174. [PubMed: 8906491]

55. Marson L, Platt KB, McKenna KE. CNS Innervation of the penis as revealed by the transneuronal transport of pseudorabies virus. Neurosci 1993;55:263-280.

56. McCarthy MM, Kleopoulos SP, Mobbs CV, Pfaff DW. Infusion of antisense oligodeoxynucleotides to the oxytocin receptor in the ventromedial hypothalamus reduces estrogen-induced sexual receptivity and oxytocin receptor binding in the female rat. Neuroendocrinol 1994;59(5):432-440.

57. McCarthy MM, Malik KF, Feder HH. Increased GABAergic transmission in medial hypothalamus facilitates lordosis but has the opposite effect in preoptic area. Brain Res 1990;507(1):40-44. [PubMed: 2302578]

58. McCarthy MM, Pfaff DW, Schwartz-Giblin S. Midbrain central gray GABAA receptor activation enhances, and blockade reduces, sexual behavior in the female rat. Exp Brain Res 1991;86(1):108116. [PubMed: 1661679]

59. McKenna, KE.; Marson, L. Spinal and brainstem control of sexual function. In: Jordan, D., editor. Central Control of Autonomic Function. Harwood Academic Publishers; 1997. p. 151-187.

60. McKenna KE. The neurophysiology of female sexual function. World J Urol 2002;20(2):93-100. [PubMed: 12107539]

61. Mouton LJ, Holstege G. The periaqueductal gray in the cat projects to lamina VIII and the medial part of lamina VII throughout the length of the spinal cord. Exp Brain Res 1994;101(2):253-264. [PubMed: 7531157]

62. Mouton LJ, Holstege G. Segmental and laminar organization of the spinal neurons projecting to the periaqueductal gray (PAG) in the cat suggests the existence of at least five separate clusters of spinoPAG neurons. J Comp Neurol 2000;428(3):389-410. [PubMed: 11074442] 
63. Murphy AZ, Hoffman GE. Distribution of gonadal steroid receptor-containing neurons in the preoptic-periaqueductal gray-brainstem pathway: a potential circuit for the initiation of male sexual behavior. J Comp Neurol 2001;438(2):191-212. [PubMed: 11536188]

64. Olster DH. Ibotenic acid-induced lesions of the medial preoptic area/anterior hypothalamus enhance the display of progesterone-facilitated lordosis in male rats. Brain Res 1993;626(1-2):99-105. [PubMed: 8281457]

65. Orr R, Marson L. Identification of CNS neurons innervating the rat prostate: A transneuronal tracing study using pseudorabies virus. J Auto Nerv Sys 1998;72:4-15.

66. Ortege-Villalobos M, Garcia-Bazan M, Solano-Flores LP, Ninomiya-Alarcon JG, Guevara-Guzman R. Vagus nerve afferent and efferent innervation of the rat uterus: an electrophysiological and HRP study. Brain Res Bull 1900;25:365-371.

67. Papka RE, Williams S, Miller KE, Copelin T, Puri P. CNS location of uterine-related neurons revealed by trans-synaptic tracing with pseudorabies virus and their relation to estrogen receptorimmunoreactive neurons. Neurosci 1998;84(3):935-952.

68. Pfaff DW, Sakuma Y. Deficit in the lordosis reflex of female rats caused by lesions in the ventromedial nucleus of the hypothalamus. J Physiol 1979;288:203-210. [PubMed: 469716]

69. Pfaff DW, Sakuma Y. Facilitation of the lordosis reflex of female rats from the ventromedial nucleus of the hypothalamus. J Physiol 1979;288:189-202. [PubMed: 469715]

70. Pfaff, DW.; Schwartz-Giblin, S.; McCarthy, MM.; Kow, L-M. Cellular and molecular mechanisms of female reproductive behavior. In: Knobil, E.; Neill, JD., editors. The physiology of reproduction. New York: Raven Press, Ltd; 1994. p. 107-220.

71. Pfaus JG. Frank A. Beach award. Homologies of animal and human sexual behaviors. Horm Behav 1996;30(3):187-200. [PubMed: 8918675]

72. Pfaus JG, Heeb MM. Implications of immediate-early gene induction in the brain following sexual stimulation of female and male rodents. Brain Res Bull 1997;44(4):397-407. [PubMed: 9370204]

73. Pfaus JG, Marcangione C, Smith WJ, Manitt C, Abillamaa H. Differential induction of Fos in the female rat brain following different amounts of vaginocervical stimulation: modulation by steroid hormones. Brain Res 1996;741(1-2):314-330. [PubMed: 9001738]

74. Platt KB, Mare CJ, Hinz PN. Differentiation of vaccine strains and field isolates of pseudorabies (Aujeszky's disease) virus: thermal sensitivity and rabbit virulence markers. Arch Virol 1979;60(1): 13-23. [PubMed: 226030]

75. Polston EK, Erskine MS. Patterns of induction of the immediate-early genes c-fos and egr-1 in the female rat brain following differential amounts of mating stimulation. Neuroendocrinol 1995;62(4): 370-384.

76. Risold PY, Fellmann D, Lenys D, Bugnon C. Coexistence of acetylcholinesterase-,human growth hormone-releasing factor(1-37)-, alpha-melanotropin- and melaninconcentrating hormone-like immunoreactivities in neurons of the rat hypothalamus: a light and electron microscope study. Neurosci Lett 1989;100(1-3):23-28. [PubMed: 2548128]

77. Rizvi TA, Ennis M, Shipley MT. Reciprocal connections between the medial preoptic area and the midbrain periaqueductal gray in rat: a WGA-HRP and PHA-L study. J Comp Neurol 1992;315(1): 1-15. [PubMed: 1371779]

78. Rizvi TA, Murphy AZ, Ennis M, Behbehani MM, Shipley MT. Medial preoptic area afferents to periaqueductal gray medullo-output neurons: a combined Fos and tract tracing study. J Neurosci 1996;16(1):333-344. [PubMed: 8613800]

79. Rodriguez-Sierra JF, Terasawa E. Lesions of the preoptic area facilitate lordosis behavior in male and female guinea pigs. Brain Res Bull 1979;4:513-517. [PubMed: 487205]

80. Rotto-Percelay DM, Wheeler JG, Osorio FA, Platt KB, Loewy AD. Transneuronal labeling of spinal interneurons and sympathetic preganglionic neurons after pseudorabies virus injections in the rat medial gastrocnemius muscle. Brain Res 1992;574(1-2):291-306. [PubMed: 1322222]

81. Rose JD. Responses of midbrain neurons to genital and somatosensory stimulation in estrous and anestrous cats. Exp Neurol 1975;49:639-652. [PubMed: 1239381]

82. Rose, JD. Brainstem influences on sexual behavior. In: Klemm, WR.; Vertes, RP., editors. Brainstem Influences on Sexual Behavior. New York: John Wiley \& Sons, Inc.; 1990. 
83. Rowe DW, Erskine MS. c-Fos proto-oncogene activity induced by mating in the preoptic area, hypothalamus and amygdala in the female rat: role of afferent input via the pelvic nerve. Brain Res 1993;621(1):25-34. [PubMed: 8221071]

84. Sakuma Y, Pfaff DW. Facilitation of female reproductive behavior from mesensephalic central gray in the rat. Am J Physiol 1979;237(5):R278-R284. [PubMed: 495775]

85. Sakuma Y, Pfaff DW. Modulation of the lordosis reflex of female rats by LHRH, its antiserum and analogs in the mesencephalic central gray. Neuroendocrinol 1983;36(3):218-224.

86. Sansone GR, Gerdes CA, Steinman JL, Winslow JT, Ottenweller JE, Komisaruk BR, Insel TR. Vaginocervical stimulation releases oxytocin within the spinal cord in rats. Neuroendocrinol 2002;75 (5):306-315.

87. Saper CB, Swanson LW, Cowan WM. The efferent connections of the ventromedial nucleus of the hypothalamus of the rat. J Comp Neurol 1976;169(4):409-442. [PubMed: 61975]

88. Schramm LP, Strack AM, Platt KB, Loewy AD. Peripheral and central pathways regulating the kidney: a study using pseudorabies virus. Brain Res 1993;616(1-2):251-262. [PubMed: 7689411]

89. Schwartz-Giblin S, McCarthy MM. A sexual column in the PAG? Trends Neurosci 1995;18(3):129. [PubMed: 7754523]

90. Simerly RB, Swanson LW. The organization of neural inputs to the medial preoptic nucleus of the rat. J Comp Neurol 1986;246(3):312-342. [PubMed: 3517086]

91. Simerly RB, Swanson LW. Projections of the medial preoptic nucleus: a Phaseolus vulgaris leucoagglutinin anterograde tract-tracing study in the rat. J Comp Neurol 1988;270(2):209-242. [PubMed: 3259955]

92. Standish A, Enquist LW, Escardo JA, Schwaber JS. Central neuronal circuit innervating the rat heart defined by transneuronal transport of pseudorabies virus. J Neurosci 1995;15(3):1998-2012. [PubMed: 7891147]

93. Sugaya K, Matsuyama K, Takakusaki K, Mori S. Electrical and chemical stimulations of the pontine micturition center. Neurosci Lett 1987;80(2):197-201. [PubMed: 3683977]

94. Tetel MJ, Getzinger MJ, Blaustein JD. Fos expression in the rat brain following vaginal-cervical stimulation by mating and manual probing. J Neuroendocrinol 1993;5(4):397-404. [PubMed: 8401563]

95. Vanderhorst VG, Mouton LJ, Blok BF, Holstege G. Distinct cell groups in the lumbosacral cord of the cat project to different areas in the periaqueductal gray. J Comp Neurol 1996;376(3):361-385. [PubMed: 8956105]

96. Van Bockstaele EJ, Aston-Jones G, Pieribone VA, Ennis M, Shipley MT. Subregions of the periaqueductal gray topographically innervate the rostral ventral medulla in the rat. J Comp Neurol 1991;309(3):305-327. [PubMed: 1717516]

97. Veening JG, Coolen LM. Neural activation following sexual behavior in the male and female rat brain. Behav Brain Res 1998;92(2):181-193. [PubMed: 9638960]

98. Veronneau-Longueville F, Rampin O, Freund-Mercier MJ, Tang Y, Calas A, Marson L, McKenna KE, Stoeckel ME, Benoit G, Giuliano F. Oxytocinergic innervation of autonomic nuclei controlling penile erection in the rat. Neurosci 1999;93(4):1437-1447.

99. Wagner CK, Clemens LG. Projections of the paraventricular nucleus of the Vhypothalamus to the sexually dimorphic lumbosacral region of the spinal cord. Brain Res 1991;539(2):254-262.

[PubMed: 1711393]

100. Wagner CK, Clemens LG. Neurophysin-containing pathway from the paraventricular nucleus of the hypothalamus to a sexually dimorphic motor nucleus in lumbar spinal cord. J Comp Neurol 1993;336(1):106-116. [PubMed: 8254108]

101. Whipple B, Komisaruk BR. Elevation of pain threshold by vaginal stimulation in women. Pain 1985;21(4):357-367. [PubMed: 4000685]

102. Yang LY, Clements LG. MPOA lesions affect female pacing of copulation in rats. Behav Neurosci 2000;114(6):1191-1202. [PubMed: 11142651]

103. Zemlan FP, Kow LM, Pfaff DW. Effect of interruption of bulbospinal pathways on lordosis, posture, and locomotion. Exp Neurol 1983;81:177-194. [PubMed: 6861946] 

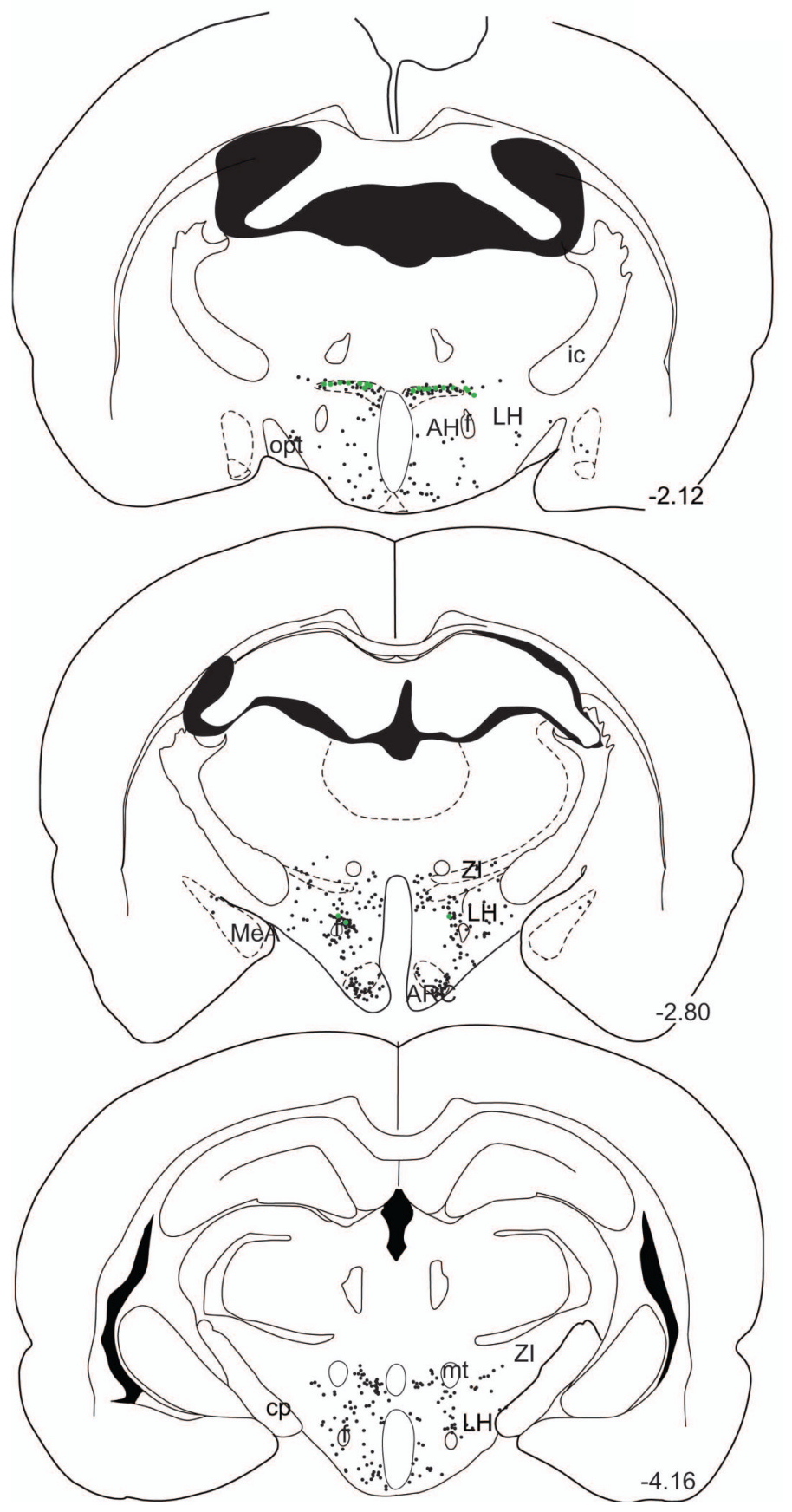

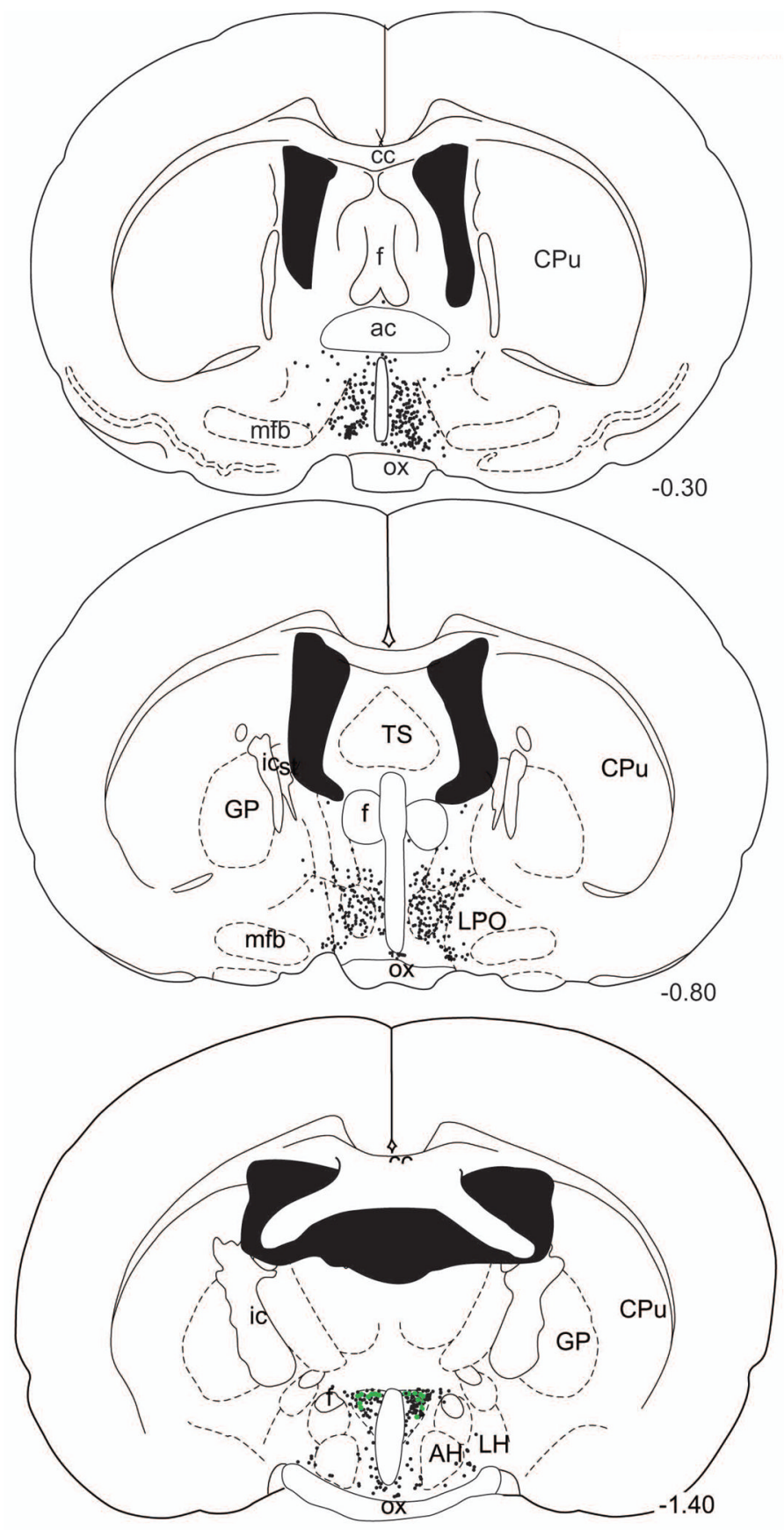

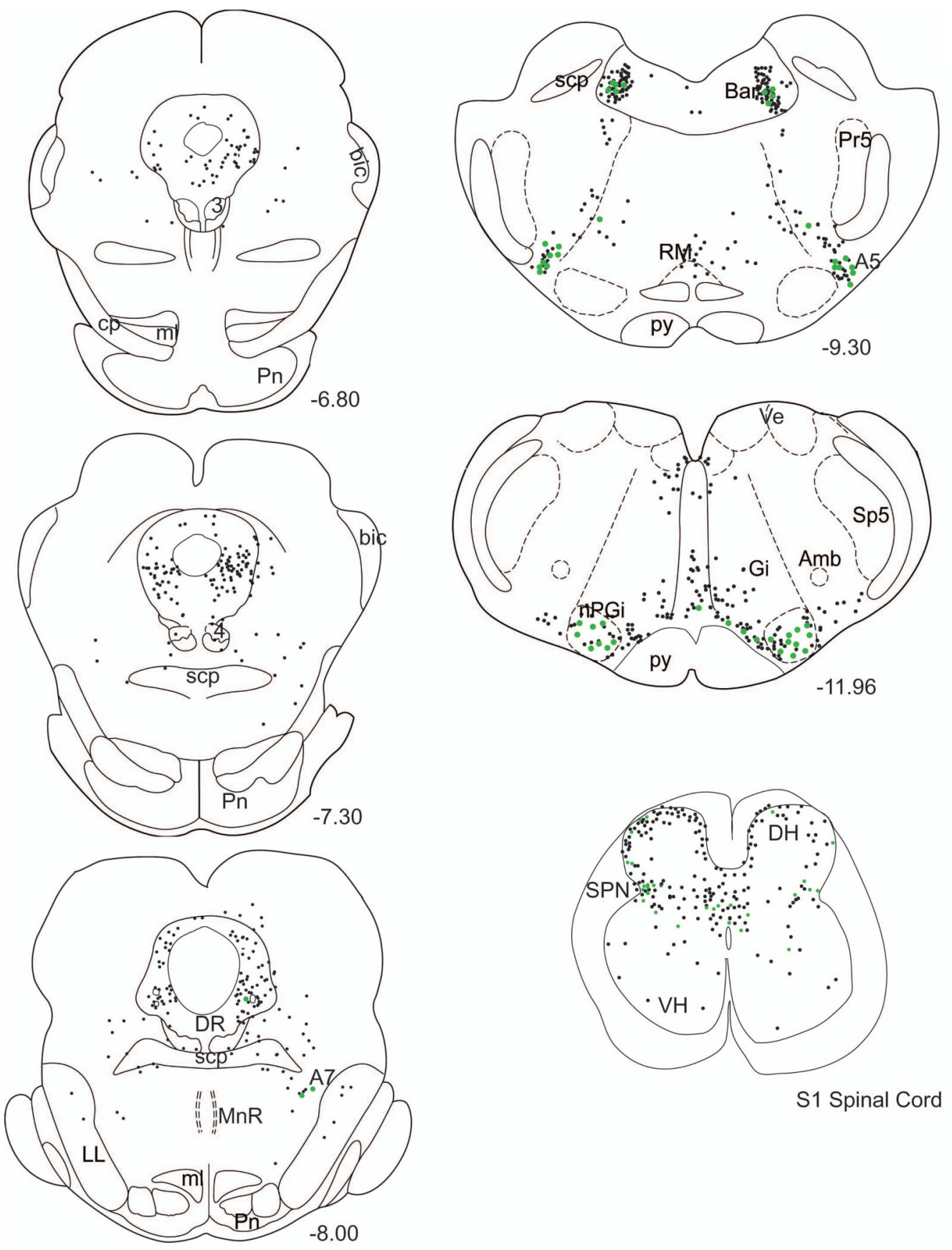

Figure 1.

Distribution of PRV transynaptically labeled cells through the brain and spinal cord 4 days [green dots] and 5 days [black dots] after injection into the clitoris and vagina. These drawings were made from an animal which had a moderate amount of labeling. The number at the bottom of each drawing indicates the distance $(\mathrm{mm})$ from Bregma. Abbreviations:- 3 - oculomotor nucleus, 4 - trochlear nucleus, A5 and A7 - noradrenergic cell groups, $\mathrm{AH}$ - anterior hypothalamic area, Ac - anterior commissure, Amb - ambiguus nucleus, ARC - arcuate hypothalamic nucleus, Bar - Barrington's nucleus, bic - brachium of the inferior colliculus, cc - corpus callosum, cp - cerebral peduncle, Cpu caudate putamen, DH - dorsal horn, DR - dorsal raphe nucleus, Ic - internal capsule, $\mathrm{f}$ - fornix, Gi - gigantocellular reticular nucleus, GP- globus 
pallidus, LH - lateral hypothalamic area, LL - lateral lemniscus, LPO - lateral preoptic area, MeA - medial amygdaloid nucleus, $\mathrm{mfb}$ - medial forebrain bundle, $\mathrm{ml}$ - medial lemniscus, $\mathrm{MnR}$ - median raphe nucleus, $\mathrm{mt}$ - mammillothalamic tract, $\mathrm{nPGi}$ - nucleus paragigantocellularis, opt - optic tract, ox - optic chiasm, Pr5 - principal sensory trigeminal nucleus, Pn - pontine nucleus, py - pyramids, RM - raphe magnus, scp - superior cerebellar peduncle, Sp5 - spinal trigeminal tract, SPN - sacral parasympathetic nucleus, st - stria terminalis, TS - triangular septal nucleus, Ve -vestibular nuclei, VH - ventral horn, ZI - zona incerta. 

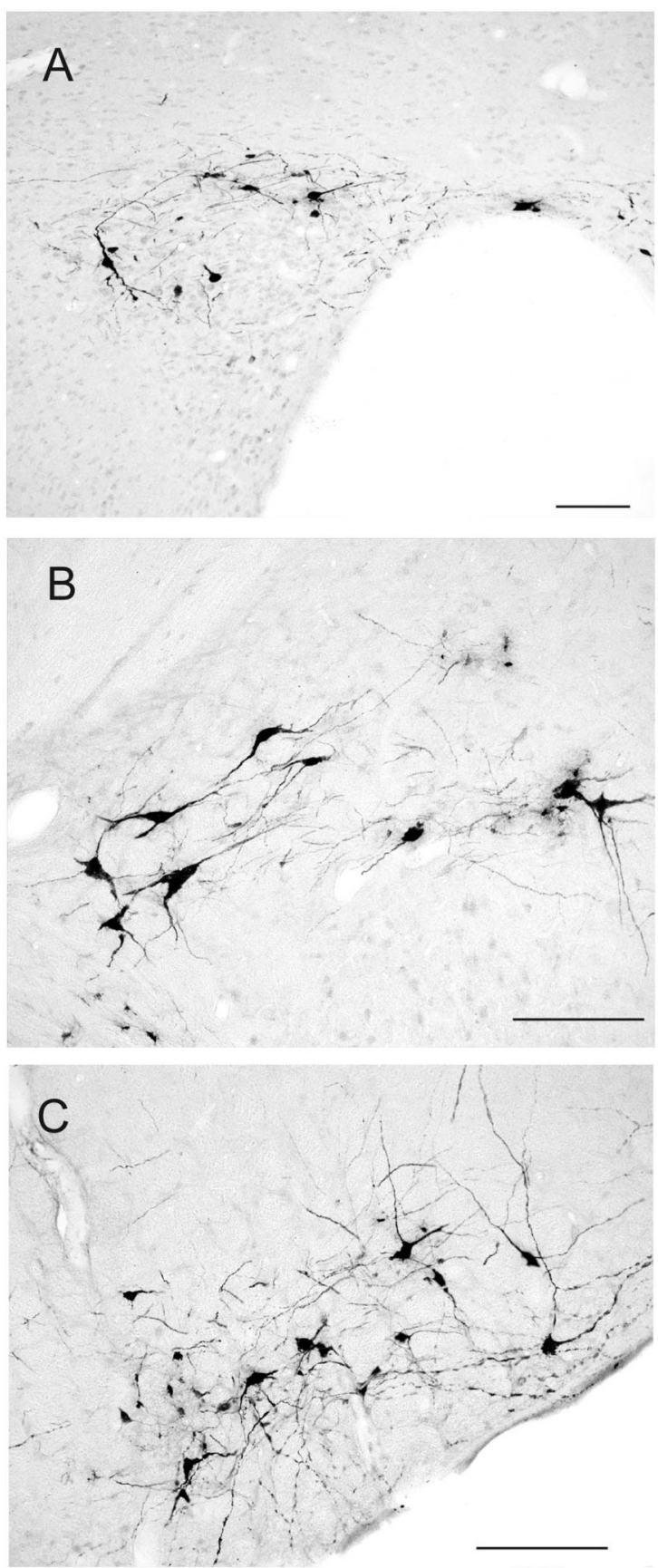

Figure 2.

Photomicrographs showing PRV labeled cells in the brain 4 days after injection into the clitoris and vagina. [A] PRV labeled cells in the paraventricular nucleus of the hypothalamus. [B] PRV labeled cells in the A5 region. [C] PRV labeled cells in the nucleus paragigantocellularis. Scale bar $=150 \mu \mathrm{m}$ 

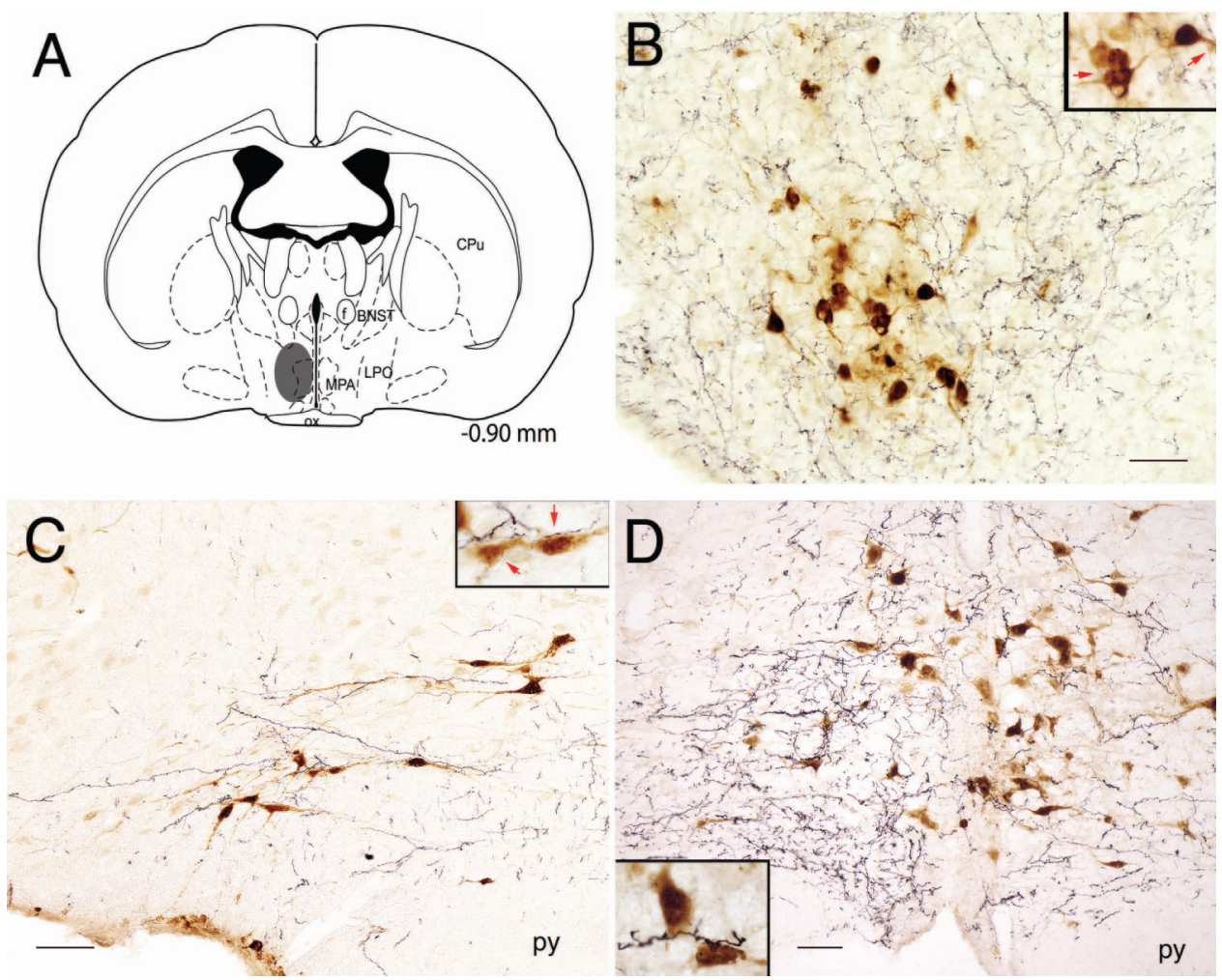

Figure 3.

Photomicrographs showing medial preoptic area (MPO, $[\mathrm{A}])$ output to the ventromedial nucleus [B], nucleus paragigantocellularis [C] and raphe magnus [D] and PRV labeled cells in the brain 5 days after injection into the clitoris and vagina. Figure A shows the location of the center of the BDA injection site in the MPO at $-0.9 \mathrm{~mm}$ caudal to bregma. Inserts in each photomicrograph show high power examples of the close association of the PRV neurons with BDA labeled fibers and varicosities (arrows). Abbreviations:- BNST - bed nucleus of stria terminalis, Cpu - caudate putamen, f- fornix, LPO - lateral preoptic area, MPA - medial preoptic nucleus, ox - optic chiasm. Scale bar $=100 \mu \mathrm{m}$ 

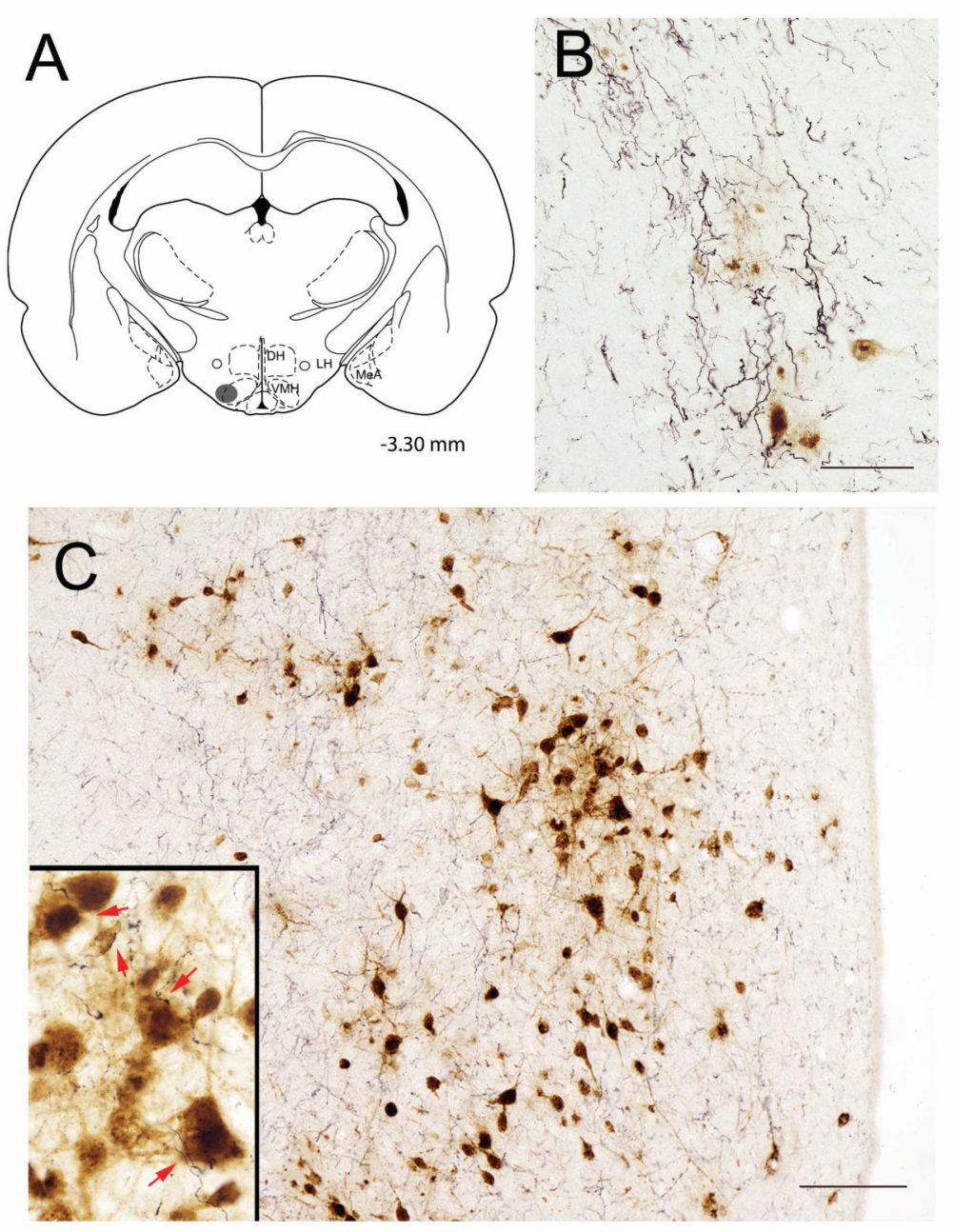

Figure 4.

Photomicrographs showing ventromedial nucleus (VMN, [A]) output to Barrington's nucleus $[B]$ and the preoptic area [C] and PRV labeled cells in the brain 5 days after injection into the clitoris and vagina. Figure A shows the location of the center of the BDA injection site in the ventromedial nucleus of the hypothalamus at -3.30 caudal to bregma. Insert [C] shows an example of the close association of the PRV neurons with BDA labeled fibers and varicosities (arrows). Abbreviations:- DH - dorsal hypothalamus, LH - lateral hypothalamus, MeA medial amygdala, VMH - ventromedial hypothalamus. Scale bar $=150 \mu \mathrm{m}$ 

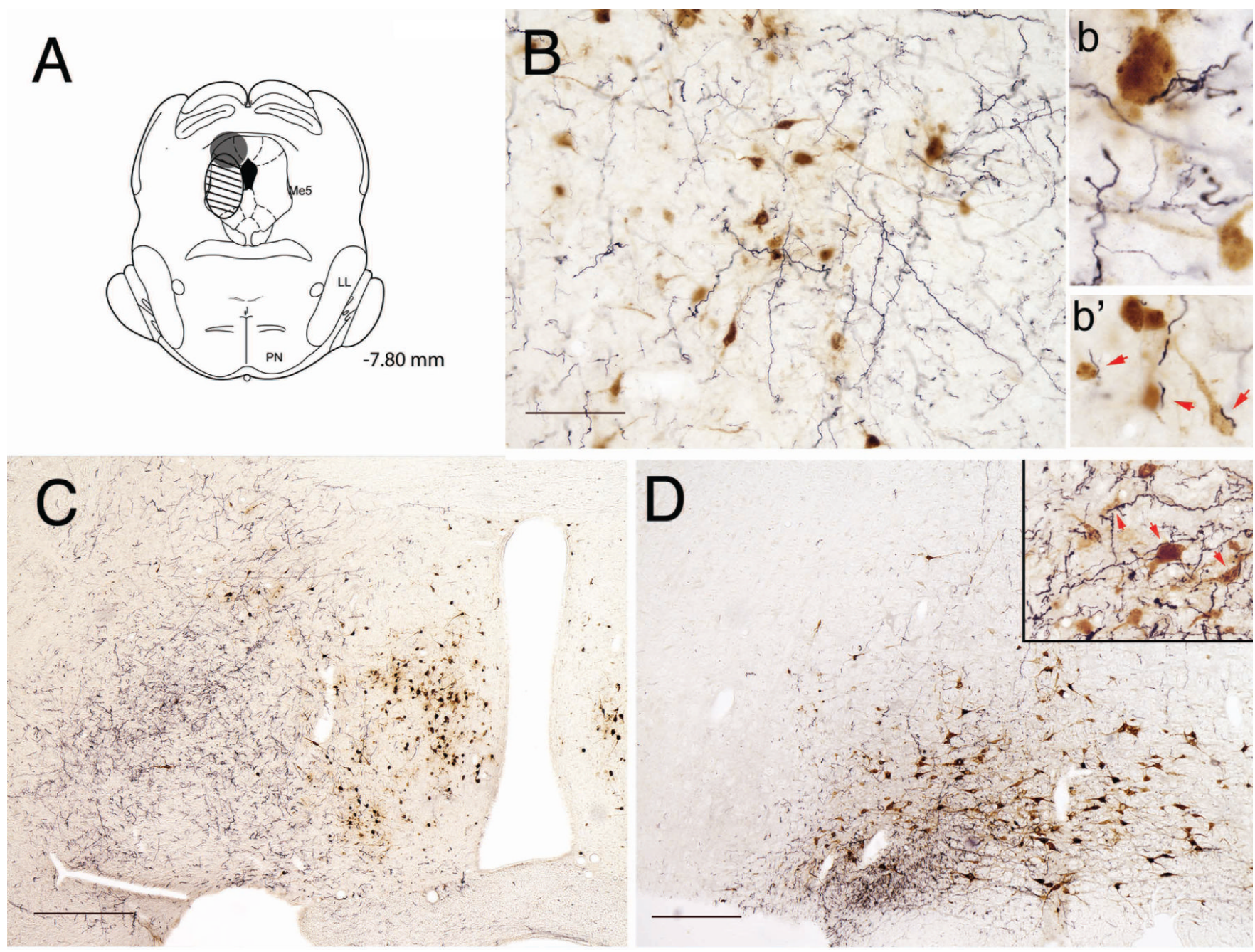

Figure 5.

Photomicrographs showing periaqueductal gray (PAG, $[\mathrm{A}]$ ) output to the lateral preoptic area [B, high magnification; and C low magnification] and to the ventral medulla [D] and PRV labeled cells in the brain 5 days after injection into the clitoris and vagina. Figure A shows the location of the BDA injection sites which included either the dorsal (solid circle) or lateral/ ventrolateral (hatched oval) PAG. Inserts [ $b$ and b' and insert in figure D] show examples of the close association of PRV neurons with BDA labeled fibers and varicosities (arrows).

Abbreviations:- LL - lateral lemniscus, Me5 - mesencephalic trigeminal nucleus, $\mathrm{PN}$ - pontine nucleus. Scale bar $=150 \mu \mathrm{m}[\mathrm{C}$ and D]; Scale bar $=500 \mu \mathrm{m}[\mathrm{B}]$. 